\title{
Agricultural Environmental Efficiency and Agricultural Environmental Kuznets Curve Based on Technological Gap: the Case of China
}

\author{
Yan Wang ${ }^{1}$, Neng Shen ${ }^{2 *}$ \\ ${ }^{1}$ School of Business, East China University of Science and Technology, \\ Shanghai 200237, Republic of China \\ ${ }^{2}$ School of Business, Soochow University, Suzhou 215021, Republic of China
}

Received: 9 December 2015

Accepted: 6 February 2016

\begin{abstract}
With regards to the interchanging features of agricultural pollution and its negative impacts on China's eco-environment such as environmental degradation, this paper, by fully taking into consideration the gap in environmental technology, incorporated the extended SBM directional distance function and Metaconstraints efficiency function to estimate China's agricultural environmental efficiency (roughly three regions: eastern, central, and western China), and employed the panel model to study the environmental Kuznets curve's (EKC) characteristics and the causes of regional differences in agricultural environmental efficiency under levels of different environmental technology. The study showed that, due to the significant differences in agricultural environmental production technology among the three different regions, agricultural environmental efficiency presented a pattern of progressive decline, for instance; eastern China $>$ western China > central China. Although the agricultural environmental technology of eastern China can reach $96.92 \%$ of the potential meta-constraint technology level, agricultural environmental technology of central and western China only reach $83.71 \%$ and $79.37 \%$ of the potential meta-technology constraint, respectively. The EKC curve of agricultural environmental efficiency was proved to be supportive of the circumstances in China; however, as a result of the gap in environmental technology, the EKC curves of different regions presented different turning points and stages. In addition to agricultural economic growth, openness of trade, proportion of agriculture, agricultural technological level, income gap, and fiscal support to agriculture have a significant effect on agricultural environmental efficiency, but both the impact direction and the impact extent of these factors on agricultural environmental efficiency are different.
\end{abstract}

Keywords: agricultural environmental efficiency, technological gap, EKC curve, meta-constraints, SBM

\section{Introduction}

Since China's reform and opening up, the country's agricultural economy has made enormous accomplishments

*e-mail: sndlu@163.com and fed a fifth of the world's population on less than a $10^{\text {th }}$ of the planet's arable land. This in itself is a powerful response to the question "Who will feed China?", not to mention that it has successfully adapted to the impacts imposed on agriculture by economic transition and made tremendous contributions to the transformation from traditional industry to modern industry. However, such 
achievements have been made at the cost of resources and the environment. On the one hand, we are approaching the threshold of the maximum capacity of our land resources as a country. We are also constantly experiencing an increasingly intensified pressure to protect arable land, as our per capita arable land area is only $40 \%$ of the world average ( $126^{\text {th }}$ in the world).

On the other hand, with the pursuit of agricultural yield in mind, the shortage of agricultural arable land resources has directly led to the overuse of chemical fertilizers and pesticides, and, as a result of the irrational input-output ratio, agriculture has already become "the industry with the most extensive non-point source pollution" in China. Agricultural pollution has not only led to the degradation of the environment and directly threatened human health, food safety, national ecological security, and the international trade of agricultural products, but also has caused immeasurable economic loss and social costs and severely hindered the sustainable development of the "three-part agricultural (agriculture, rural areas, and farmers) economy".

However, currentstudies on theagriculturalenvironment mainly focus on engineering and technology and excessively emphasize the technological characterization and causes of the agricultural environment. As a result, agricultural studies tend to be treated as a natural science, while the economic and sociological roots behind the technological characterization are largely neglected. Such a cognitive bias obviously goes against rational decisionmaking on the agricultural environment. The author expects that an effective evaluation would be conducted on the sustainable development status of agriculture from a more macroscopic perspective, so as to investigate the factors promoting China's agricultural economic growth other than those traditional input factors. If resources are fixed and environmental pollution is an unavoidable fact, then what is the relationship trend between the existing resources and environment along with agricultural growth? The answers to these questions are important in terms of both theoretical and practical significance for resolving the contradiction among the existing resources, environment, and agricultural growth, and for realizing the sustainable development of agriculture.

\section{Literature Review}

As global environmental issues become increasingly prominent, some scholars have begun to pay attention to the relationship between environmental pollution and economic growth. Grossman and Krueger (1995) [1] stated that the relationship between economic growth, resource consumption, and pollution emissions can be characterized by an inverted U-shaped curve, named the environmental Kuznets curve (EKC). Based on the EKC hypothesis, natural resource consumption and pollution emissions will increase with the increase of income before reaching a certain income threshold; however, after reaching the income threshold, resource consumption will decrease and environmental quality will improve with the continuous increase of income. Soon afterward, scholars began to verify the existence of this EKC curve with the data collected in their countries from different aspects (Kahn, 1998 [2]; Soytas, 2009 [3]; Park, 2011 [4]; Sephton, 2013 [5]; Giovanis, 2013 [6]; Wang, 2013 [7]; Muhammad, 2014 [8]; Wang, 2015[9]; Nicholas, 2015[10]; Mehdi, 2015[11]; and Jungho, 2015 [12]), but the studies were mainly concentrated in the industrial field, and EKC studies in the agricultural field were rarely seen (Zhanghui, 2011 [13]; Cao Dayu et al., 2011 [14]; Wang, 2011 [15]; Abdoulkarim, 2014 [16]; and Silvia, 2014 [17]). Moreover, no consistent conclusion has been reached with respect to the existence of the EKC curve in China's agriculture and its characteristics (if it does exist).

The problem with traditional EKC studies is twofold. First, the relationships between agricultural output value and pollution emissions have been treated simply from the angle of output. This has largely neglected production processes and links by which agricultural input is transformed into an agricultural output value and pollution emissions while, as a matter of fact, the efficiency improvement of the production process is very likely to also improve environmental quality on the basis of increasing agricultural output value (Zaim et al., 2000 [18]). Second, the selection of pollution indicators will largely affect the morphological differences of the EKC curve. One of the common characteristics of previous literature is that they all employ the pollution intensity and the absolute pollution load of various individual pollutants alone as the quality degradation indicators of agricultural environment, so it's inevitable that entirely different conclusions have been reached with respect to different pollutants, not to mention that they cannot fully reflect the increasingly complicated problem of "threedimensional agricultural pollution." Considering that these elusive conclusions can neither investigate the effects of agricultural growth on resource consumption and environmental pollution as a whole nor provide a consistent basis for decision-making, it's necessary to redefine the explained variable (environmental indicator) in the EKC model using agricultural environmental efficiency in order to reflect the production processes from agricultural input to agricultural output value (pollution discharge).

With the increasingly serious agricultural pollution emissions, studies on agricultural growth efficiency have undergone a rough transition from studies on a single resource constraint to studies on agricultural environmental efficiency as restrained by both resources and the environment. The literature has been based on two ideas about dealing with environmental factors. First, the costs of pollution control are processed as an input variable, however, in empirical studies it's not only difficult to distinguish between the input factors used for producing the desirable output and those used for pollution control, but can also distort the actual input-output relationship (Hailu et al., 2001 [19]). Second, the pollution emissions have been treated as a weakly disposable undesirable output, 
to be produced together with the desirable output (Fare et al., 2007 [20]). With regard to the agricultural sector, Falavigna (2013) [21] use directional output distance function (DODF) to evaluate agricultural environmental efficiency $\mathrm{p}$ by considering pollutant emission to be an undesirable output. Abedullah (2010) [22] attempts to estimate the environmental efficiency of rice production by employing the translog stochastic production frontier approach. Li Gucheng (2011) [23] employed the nonradial and non-angular SBM directional distance function to incorporate the environmental pollution variables into the evaluations of agricultural technological efficiency at both national and provincial levels. However, in terms of calculating agricultural efficiency, an underlying assumption made by all previous reference literature investigating the root of the technological inefficiency of a decision-making unit is that all the decision-making units face the same or similar technological constraints, such as the assumption of technological homogeneity. In consideration of the obvious differences among different decision-making units in terms of resource endowment, agricultural system, and developmental level, there must be certain degrees of difference in the environmental technological constraints of different regions. In order to address this problem, Hayami (1969) [24] first came up with the concept of the meta-production function. In recent years, the concept of meta-constraints productivity index has been adopted in some literature in efficiency calculations in various fields (Bo, 2012 [25]; Tunca, 2013 [26]; Wang, 2013 [27]; Susila, 2015 [28]; Yu, 2015 [29]; Zou, 2015 [30]). Among them, Wang Qunwei (2010) [31] and Liu Yuhai (2011) [32] employed the method to calculate regional (industrial) environmental efficiency but, unfortunately, all of the literature neglected the effect of the differences in environmental technological constraints on the evaluation of agricultural environmental efficiency.

In order to compensate for the deficiencies in previous literature, first the extended SBM directional distance function and meta-frontier efficiency function were both incorporated into our study in order to calculate Chinese environmental efficiency so as to fully take into consideration the effects of any environmental technological gaps on the evaluation of agricultural environmental efficiency. Second, the panel model was employed to test the EKC curve characteristics and extract the factors influencing agricultural environmental efficiency under different environmental technological levels.

\section{Estimating Agricultural Environmental Efficiency}

\section{SBM Directional Distance Function}

In order to overcome the deficiency of traditional data envelopment analysis (DEA) in radial and angular processing, Fare and Grosskopf (2009) [33] refined the non-radial and non-angular SBM efficiency model proposed by Tone (2001) [34], and put forward a more generalized non-radial and non-angular directional distance function. The method directly incorporates the slack variable into the target function. On the one hand, this can overcome the error caused by neglecting the effect of undesirable output on efficiency evaluation and, on the other hand, solve the input-output relaxation problem. Based on the models proposed by Tone (2003) [35] and Fukuyama and Weber (2009) [36], the paper defined the SBM directional distance function as restrained by both resources and environment:

$$
\begin{gathered}
S_{V}^{t}\left(x^{t, k^{\prime}}, y^{t, k^{\prime}}, b^{t, k^{\prime}}, g^{x}, g^{y}, g^{b}\right)= \\
=\max _{s^{x}, s^{y}, s^{b}} \frac{\frac{1}{N} \sum_{n=1}^{N} \frac{s_{n}^{x}}{g_{n}^{x}}+\frac{1}{M+1}\left[\sum_{m=1}^{M} \frac{s_{m}^{y}}{g_{m}^{y}}+\sum_{i=1}^{I} \frac{s_{i}^{b}}{g_{i}^{b}}\right]}{2} \\
\text { s.t. } \sum_{k=1}^{K} z_{k}^{t} x_{k n}^{t}+s_{n}^{x}=x_{k^{\prime} n}^{t}, \forall n ; \sum_{k=1}^{K} z_{k}^{t} y_{k m}^{t}-s_{m}^{y}= \\
=y_{k^{\prime} m}^{t}, \forall m ; \sum_{k=1}^{K} z_{k}^{t} b_{k i}^{t}+s_{i}^{b}=b_{k^{\prime}}^{t}, \forall i ; \\
\sum_{k=1}^{K} z_{k}^{t}=1, z_{k}^{t} \geq 0, \forall k ; s_{n}^{x} \geq 0, \forall n ; s_{m}^{y} \geq 0, \forall m ; s_{i}^{b} \geq 0, \forall i
\end{gathered}
$$

...where $x^{t, k^{\prime}}, y^{t, k^{\prime}}, b^{t, k^{\prime}}$ represent the input and output vectors of region $k^{\prime},\left(s_{n}^{x}, s_{m}^{y}, s_{i}^{b}\right)$ represent input-output relaxation vectors, $\left(g^{x}, g^{y}, g^{b}\right)$ represent the direction vectors when the values of good output extension and bad output and input compression are positive. Considering that the constraint of linear programming is the equation, when $\left(s_{n}^{x}, s_{m}^{y}, s_{i}^{b}\right)$ are all greater than 0 , it means that undesirable input and output are greater than the confined input and output, while desirable output is less than the confined output. So, $\left(s_{n}^{x}, s_{m}^{y}, s_{i}^{b}\right)$ represent the values of input redundancy, the overproduction of undesirable output, and the underproduction of desirable output. Furthermore, the target efficiency is the maximization of the mean value of input inefficiency and output (both desirable output and undesirable output) inefficiency. Given that a lower environmental inefficiency value represents a higher efficiency level, in order to adjust the results to traditional habits, we employed the formula $E=1 /(1+I E)$ to convert the environmental inefficiency value into the environmental efficiency value, which resulted in the converted value falling to between 0 and 1 .

\section{Meta-Constraints Efficiency Function}

When employing the traditional DEA method to evaluate the efficiency of decision-making units, there is an assumption that all the decision-making units are facing a homogeneous technological level. However, when studies sample different regions, the heterogeneity of the technological constraints of the different regions becomes an inevitable consequence of the huge differences among these different regions in terms of resource endowment, economic system, and economic structure. To solve this 
problem, Battese and Rao (2002) [37] constructed the Metaconstraints production function model so as to first divide the decision-making units into different groups. They then constructed meta constraints and group constraints by the stochastic frontier analysis (SFA) method and finally calculated both meta-technology efficiency and group technology efficiency. On such a basis, Seiford (2002) [38] and O'Donnell et al. (2008) [39] further developed the meta constraints and group constraints analysis framework based on the DEA method. The basic idea of the method is to construct group constraints so that different groups respectively correspond to matching technological constraints and jointly construct meta constraints.

For a decision-making unit (DMU) in the DEA model, input $\left(x \in R_{+}^{M}\right)$ brings about output $\left(y \in R_{+}^{L}\right)$. When all the decision-making units are taken into account, a meta-technology set they face is $T^{\text {meta }}=\{(x, y) \mid x \geq 0$; $y \geq 0 ; x \cdot$ can $\cdot$ produce $\cdot y\}$, so the production possibility set $P$ is defined as $P^{\text {meta }}(x)=\left\{y \mid(x, y) \in T^{\text {meta }}\right\}$, i.e., its upper constraint is the meta constraint. Now the metatechnology efficiency-based meta-distance function can be expressed as:

$$
0 \leq D^{\text {meta }}(x, y)=\inf _{\theta}\left\{\theta<0 \mid\left(\frac{y}{\theta}\right) \in T(x)\right\}=T E^{\text {meta }}(x, y) \leq 1
$$

In the same way, if a certain standard is to be employed to divide all the decision-making units into $k$ subgroups, each sample is faced with the technological set of the group to which it belongs, i.e., $T^{k}=\{(x, y) \mid x \geq 0 ; y \geq 0$; $x \cdot$ can $\cdot$ produce $\cdot y\}$, so the production possibility set can be defined as $P^{k}(x)=\left\{y \mid(x, y) \in T^{k}\right\}$, i.e., its upper constraint is the group constraint. Now the group technology efficiency-based group distance function can be expressed as:

$$
0 \leq D^{k}(x, y)=\inf _{\theta}\left\{\theta>0 \mid\left(\frac{y}{\theta}\right) \in T^{k}(x)\right\}=T E^{\text {group }-k}(x, y) \leq 1
$$

Battese et al. (2004) pointed out the basic characteristics of group constraints: first, for any group $k$, if $(x, y) \in T^{k}$, then $(x, y) \in T$; second, if $(x, y) \in T$, then there must be a group $k$ which satisfies $(x, y) \in T^{k}$; third, the meta-technology set certainly envelopes all the group technology sets, i.e., $T^{\text {meta }}=\left\{T^{1} \cup T^{2} \cup L \cup T^{\mathrm{k}}\right\}$, and the meta constraint is an envelope curve no lower than the group constraint; fourth, if $P^{\text {meta }}(x)$ is convex, it does not mean that $P^{k}(x)$ is also convex. It can be known from Formulae (2) and (3) that $D^{\text {meta }}(x, y) \leq D^{k}(x, y) \Rightarrow$ $T E^{\text {meta }}(x, y) \leq T E^{\text {group }-k}(x, y)$.

Based on the ratio of the actual output level under the group constraint to the actual output level under the meta constraint, the meta-technology ratio (MTR) can be obtained, as expressed by the following operation formula:

$$
0 \leq \operatorname{MTR}^{k}(x, y)=\frac{D^{\text {meta }}(x, y)}{D^{k}(x, y)}=\frac{T E^{\text {meta }}(x, y)}{T E^{\text {group }-k}(x, y)} \leq 1
$$

Formula (4) represents the gap between the production technology of a decision-making unit under group $k$ and its production technology under the meta constraint under the same factor input level, which is caused by a specific group system structure. If the MTR value is higher, it indicates that the actual technology level of the decisionmaking unit is higher, i.e., the production technology used by the decision-making unit is more approximate to the potential production technology level, and vice versa.

Formula (4) can be further arranged into Formula (5), which indicates that the meta-technology efficiency can be further decomposed into two parts: one part is the group constraint's technological efficiency, and the other is the technological gap between the group constraint's and the meta-constraint's technologies.

$$
T E^{\text {meta }}(x, y)=T E^{\text {group }-k}(x, y) \times \operatorname{MTR}^{k}(x, y)
$$

Meta-technology efficiency, group technology efficiency, and meta-technology ratio can be illustrated by Fig. 1. In Fig. 1, assume that groups 1, 2, and 3 are, respectively, the three regions of China (eastern, central, and western) and the meta constraint is a convex function, then the meta-constraint technology efficiency, group constraint technology efficiency, and meta-technology ratio of Region A can be respectively represented as below $^{1}$ :

$$
\begin{gathered}
T E^{\text {meta }}(A)=\frac{O B}{O D} ; \quad T E^{\text {group }-k}(A)=\frac{O C}{O D} \\
M R T^{k}=\frac{O B / O D}{O C / O D}=\frac{O B}{O C}
\end{gathered}
$$

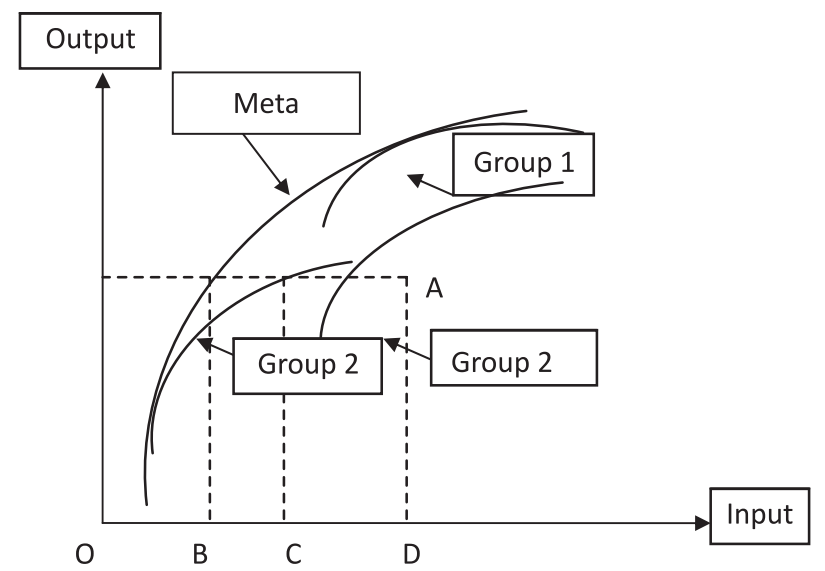

Fig. 1. Meta constraints and group constraints.

\footnotetext{
The technological efficiency of each group is calculated under the premise of taking into account undesirable pollution discharge. On that account, meta-technology efficiency may also be called meta environmental efficiency, group technology efficiency may also be called group environmental efficiency, and meta-technology ratio may also be called the meta environmental technological ratio.
} 


\section{Selection of Indicators}

In order to fully take into consideration the gap in agricultural environmental technology, throughout this paper the traditional regional division method (eastern, central, and western) was employed to divide the samples into three technologically heterogeneous groups. The samples covered 29 provinces - municipalities directly under the central government and autonomous regions of China, excluding Tibet and Hainan (partial loss of data) as well as Hong Kong, Macao, and Taiwan. Having referred to previous literature and taken into account the availability of data, we selected relevant agricultural input and output indicators in the sample period from 1998 to 2013. The data used were collected from China Statistical Yearbook, China Agriculture Yearbook, China Rural Statistical Yearbook, China Statistical Yearbook on Environment, and China Statistical Yearbook for Regional Economy (see the selection and definitions of relevant indicators below).

Input variables include six key aspects, namely labor, land, agricultural machinery, fertilizers, draught animals, and irrigation. Labor input is represented by the quantity of employment of the primary industry, and refers to the total quantity of labor force employed in farming, forestry, animal husbandry, and fishery (excluding the labor force employed in industry and service sectors in the rural area); land input is represented by the total sown area of grain crops; agricultural machinery power input is represented by the total of various power machinery used in agriculture, forestry, animal husbandry, sideline occupations and fishery (excluding those rural machinery used for nonagricultural purposes); fertilizer input mainly includes such fertilizers as phosphate-based, nitrogen-based, potassium-based, and compound fertilizers (converted by the actual applying quantity of chemical fertilizers purified volume); draught animal input is calculated by the quantity of agricultural working animals, specifically referring to those employed for the production of farming, forestry, animal husbandry, and fishery; and irrigation input is calculated by the actual effective irrigation area of each province each year, including the area of paddy fields and irrigable fields for which normal agricultural irrigation is available.

Desirable agricultural product refers to the total output value of farming, forestry, animal husbandry, and fishery of each province as represented by the constant price of 1990. Considering the necessity to maintain consistency with the general agricultural caliber in agricultural input indicators, the general total output value of agriculture was used in this paper.

Undesirable agricultural product refers to the total pollution discharge of agriculture. Having taken into consideration the availability of data and the strengths and weaknesses of various calculation methods, the unit investigation and evaluation method was employed in this paper to calculate the total agricultural non-point source pollution discharge of each province (Laisiyun, 2004 [40]). Agricultural pollution as defined in this paper mainly refers to the discharge of COD, TN, and TP in agricultural production processes, which includes four main pollution units, i.e., fertilizer loss, livestock pollution, solid agricultural organic wastes (crop straws), and rural domestic pollution. Having established the quantitative relationship among pollution discharge units, pollution production, and pollution discharge, the estimation model of agricultural non-point source pollution discharge is provided below:

$$
E_{j}=\sum_{i} E U_{i} \rho_{i j}\left(1-\eta_{i}\right) C_{i j}\left(E U_{i j}, S\right)=\sum_{i} P E_{i j} \rho_{i j}\left(1-\eta_{i}\right) C_{i j}\left(E U_{i j}, S\right)
$$

...where $E_{j}$ represents the discharge of agricultural pollutant $j, E U_{i}$ represents the indicator statistics of unit $i$, $\rho_{i j}$ represents the pollution-production intensity coefficient of pollutant $j$ of unit $i, \eta_{i}$ represents the coefficient characterizing the utilization efficiency of relevant resources, $P E_{i j}$ represents the production of pollutant $j$, and $C_{i j}$ represents the discharge coefficient of pollutant $j$ of unit $i$, which reflects the effects of the resource and geographical environment and the management system of each region on agricultural pollution discharge and is determined by the unit and spatial characteristic $S$. Based on the Manual of Agricultural Source Coefficients of the First National General Survey of Pollution Sources and the investigation of a wide range of relevant literature, this paper adjusted and modified such parameter values as various pollution-production intensity coefficients and pollution discharge coefficients. Table 1 provides a characteristic description of relevant variables.

Table 1. Average growth rates of relevant variables.

\begin{tabular}{|c|c|c|c|c|c|c|c|c|}
\hline Region & $L$ & $M$ & $S$ & $F$ & $I$ & $D$ & $Y$ & $P$ \\
\hline Nation & -0.1013 & 1.3304 & 0.0053 & 0.5478 & 0.2549 & -0.5295 & 2.1114 & 1.0177 \\
\hline East & -0.1434 & 0.5903 & -0.1578 & 0.3409 & 0.0674 & -0.6752 & 1.7073 & 0.9856 \\
\hline Middle & -0.0401 & 1.8001 & 0.1130 & 0.6441 & 0.4142 & -0.5534 & 2.3610 & 1.0278 \\
\hline West & -0.1063 & 1.6641 & 0.0811 & 0.6745 & 0.2833 & -0.3625 & 2.3077 & 1.0245 \\
\hline
\end{tabular}

Notes: $L$ is labor, $M$ is machinery, $S$ is land, $F$ is fertilizers, $I$ is irrigation, $D$ is draught, $Y$ is total output value, and $P$ is pollution. 


\section{Results of Estimation}

Meta environmental efficiency (MEE) reflects the distance from the actual output to the meta-constraint output under the same input conditions of a decisionmaking unit (DMU) when undesirable pollution discharge is taken into account, while group environmental efficiency (GEE) reflects the distance from the actual output to the group constraint of a decision-making unit (DMU). As can be seen from the mean MEE value of various groups, the sequence from high to low is successively eastern China, western China, and central China, which indicates that central and western China are witnessing an imbalance of resources and environmental and agricultural development, and that to a certain extent there is still a large amount of improvement possible with regards to environmental efficiency for both central and western China. Specifically, as far as the mean MEE is concerned, if production is to be conducted as per the potential meta constraint, the amount of efficiency improvement needed for the three groups for eastern, central, and western China are, respectively, $7.87 \%, 28.02 \%$, and $23.62 \%$. As far as mean group environmental efficiency is concerned, the highest performing province in eastern China is Zhejiang, whose corresponding GEE value and MEE value are, respectively, 0.9715 and 0.9536 , while Hebei is the least performing province, whose corresponding GEE and MEE values are, respectively, 0.9123 and 0.8113 . This suggests that, compared with the group constraint technology of eastern China, the amount of efficiency improvement needed for Zhejiang and Hebei in agricultural production are, respectively, $2.85 \%$ and $8.77 \%$; compared with the potential meta-constraint technology, the amount of efficiency improvement needed for the two provinces are, respectively, $4.64 \%$ and $18.87 \%$. Similarly, in western China compared with the group constraint technology, the amount of efficiency improvement needed for bestperforming Inner Mongolia and worst-performing Guizhou in terms of GEE in agricultural production are, respectively, $6.98 \%$ and $12.35 \%$; compared with the meta-constraint technology, the amount of efficiency improvement needed for the two provinces are, respectively, $22.35 \%$ and $30.94 \%$. In central China, compared with the group constraint technology, the amount of efficiency improvement needed for the best-performing Jilin and worst-performing Jiangxi in terms of GEE in agricultural production are, respectively, $7.69 \%$ and $11.24 \%$; compared with the meta-constraint technology, the amount of efficiency improvement needed for the two provinces are, respectively, $28.46 \%$ and $31.91 \%$.

By looking at these results we can learn that in no sample will MEE be greater than GEE, because the metaconstraint technology includes the national potential optimum-environmental production technology level, while the group constraint technology only implies the potential optimum-environmental production technology level within the group concerned.

Meta-technology ratio (MTR) reflects the gap between the group constraint environmental technology level and the meta-constraint environmental technology level. It can be seen from Table 2 that the three groups are arranged successively in the sequence of eastern, western, and central china in terms of the environmental technology gap. Specifically, the MTR of Eastern China is 0.9692, which indicates that its existing agricultural environmental technology can reach $96.92 \%$ of the potential Metaconstraint technology level. On the one hand, eastern China is a coastal region and therefore enjoys great advantages in absorbing and utilizing domestic and foreign advanced agricultural environmental-protection technology; on the other hand, both the environmental regulation level and environmental technology innovation capacity of eastern China are at the most advanced level in China. Therefore, eastern China is no doubt the leader of national agricultural environmental technology innovation, while both western and central China are facing hardly optimistic prospects in agricultural environmental technology, as the mean levels of environmental technology they have employed have only respectively reached $83.71 \%$ and $79.37 \%$ of the potential meta-technology constraint. Besides the longterm non-balanced strategy which has put pressure on the developmental capacity of both central and western China, the insufficient input of agricultural environmentalprotection capital and manpower in central and western China have also severely inhibited the intensity of agricultural environmental technology innovation in these regions, and accelerated the gap between them and eastern China in agricultural environmental technology. Among the groups of eastern China, the province with the highest mean MTR is Shanghai (0.9930), which indicates that, after incorporating the undesirable pollution discharge into the agricultural efficiency evaluation framework, Shanghai has the highest environmental technology level among the groups of eastern China, and the level of actual environmental technology it has employed can reach $99.30 \%$ of the potential meta-constraint environmental technology level. Chongqing and Hubei respectively rank the highest in terms of environmental technology level among the groups of western China and among those of central China, and the levels of actual environmental technology they have employed can respectively reach $90.14 \%$ and $87.17 \%$ of the potential meta-constraint environmental technology level.

The change rates of meta environmental efficiency (RMEE) and group environmental efficiency (RGEE) respectively reflect the relative position change between the actual production output of a DMU and the metatechnology constraint and group technology constraint within the sample period, implying the potential catch-up of environmental production technology. It can be seen from Table 2 that, among the groups of eastern China, Guangdong has shown significant improvement in terms of both RMEE and RGEE (respectively by $0.1760 \%$ and $0.2587 \%$ ), which indicates that the agricultural environmental production technology of Guangdong has undergone a significant catch-up effect. Liaoning has shown the most significant decline in terms of both RMEE and RGEE (respectively by $0.1108 \%$ and $0.2815 \%$ ), which indicates that, under the circumstances of both 
Table 2. The value of agricultural environmental efficiency (1998-2013).

\begin{tabular}{|c|c|c|c|c|c|c|}
\hline Region & $C E E$ & $M E E$ & $M T R$ & $R G E E$ & $R M E E$ & $R M T R$ \\
\hline \multicolumn{7}{|c|}{ Eastern China } \\
\hline Beijing & 0.9681 & 0.9484 & 0.9797 & 0.2187 & 0.0789 & 0.1509 \\
\hline Tianjin & 0.9650 & 0.9422 & 0.9767 & 0.1903 & 0.0762 & 0.0987 \\
\hline Hebei & 0.9123 & 0.8113 & 0.8891 & -0.0493 & 0.1434 & -0.0340 \\
\hline Shandong & 0.9473 & 0.9289 & 0.9805 & 0.0876 & 0.1873 & 0.2718 \\
\hline Shanghai & 0.9631 & 0.9564 & 0.9930 & 0.2176 & 0.0980 & 0.1983 \\
\hline Jiangsu & 0.9589 & 0.9428 & 0.9832 & 0.1675 & 0.2876 & 0.3094 \\
\hline Zhejiang & 0.9715 & 0.9536 & 0.9815 & 0.0876 & 0.1293 & 0.2803 \\
\hline Fujian & 0.9283 & 0.9052 & 0.9751 & 0.1078 & 0.2078 & 0.3870 \\
\hline Guangdong & 0.9620 & 0.9502 & 0.9877 & 0.2587 & 0.1760 & 0.2237 \\
\hline Liaoning & 0.9143 & 0.8645 & 0.9455 & -0.1108 & -0.2816 & -0.0691 \\
\hline Mean & 0.9497 & 0.9203 & 0.9692 & 0.1126 & 0.1124 & 0.1817 \\
\hline \multicolumn{7}{|c|}{ Central China } \\
\hline Jilin & 0.9231 & 0.7154 & 0.7749 & 0.3208 & 0.3021 & 0.2187 \\
\hline Heilongjiang & 0.9172 & 0.6876 & 0.7496 & 0.2983 & 0.1803 & 0.1182 \\
\hline Anhui & 0.9014 & 0.7187 & 0.7973 & -0.1495 & -0.3581 & -0.2480 \\
\hline Jiangxi & 0.8876 & 0.6809 & 0.7671 & -0.1032 & 0.2347 & -0.1573 \\
\hline Sanxi & 0.9034 & 0.7315 & 0.8097 & 0.0834 & 0.2342 & 0.2845 \\
\hline Henna & 0.9134 & 0.7042 & 0.7709 & 0.3023 & 0.4835 & 0.2994 \\
\hline Hubei & 0.8907 & 0.7765 & 0.8717 & 0.3132 & 0.2743 & 0.3002 \\
\hline Hunan & 0.9203 & 0.7443 & 0.8087 & 0.1844 & 0.2293 & 0.2935 \\
\hline Mean & 0.9071 & 0.7198 & 0.7937 & 0.1687 & 0.1725 & 0.1299 \\
\hline \multicolumn{7}{|c|}{ Western China } \\
\hline Inner Mongolia & 0.9302 & 0.7765 & 0.8347 & 0.4308 & 0.2098 & 0.3471 \\
\hline Guangxi & 0.9038 & 0.7865 & 0.8702 & 0.2128 & 0.1287 & 0.1875 \\
\hline Chongqing & 0.9292 & 0.8376 & 0.9014 & 0.3183 & 0.2906 & 0.2447 \\
\hline Sichuan & 0.8976 & 0.7884 & 0.8783 & 0.1187 & 0.2307 & 0.1650 \\
\hline Guizhou & 0.8765 & 0.6906 & 0.7879 & -0.2099 & -0.0565 & -0.1870 \\
\hline Yunnan & 0.9270 & 0.7400 & 0.7982 & 0.1594 & 0.0987 & 0.1313 \\
\hline Shanxi & 0.9076 & 0.7386 & 0.8137 & -0.1887 & 0.1765 & -0.0755 \\
\hline Gansu & 0.9132 & 0.7285 & 0.7977 & 0.3011 & 0.1308 & 0.1993 \\
\hline Qinghai & 0.9307 & 0.7466 & 0.8022 & 0.0973 & 0.2001 & 0.1623 \\
\hline Ningxia & 0.8987 & 0.7703 & 0.8571 & -0.0454 & 0.1113 & -0.0440 \\
\hline Xinxiang & 0.9203 & 0.7982 & 0.8673 & 0.2903 & 0.3121 & -0.2201 \\
\hline Mean & 0.9123 & 0.7638 & 0.8371 & 0.1350 & 0.1373 & 0.0737 \\
\hline
\end{tabular}

Notes: GEE and $R G E E$ respectively represent group environmental efficiency and its change rate, $M E E$ and $R M E E$ respectively represent meta environmental efficiency and its change rate, MTR and RMTR respectively represent meta environmental technological ratio and its change rate. 
agricultural environmental efficiency and technological catch-up having witnessed significant decline, factor input is the main source of agricultural growth for Liaoning, and improving local agricultural environmental technology and efficiency is an urgent and unavoidable problem for the agricultural development of Liaoning.

In western China, the actual agricultural growths of both Inner Mongolia and Xinjiang have benefited to a great extent from the improvement of their environmental efficiency and technological level; the RGEE of Inner Mongolia has reached $0.4308 \%$ and the RMEE of Xinjiang has reached $0.3121 \%$, from which we may conclude that the agricultural growth patterns of both Inner Mongolia and Xinjiang are technology- and efficiency-oriented.

Under the circumstance of underperforming meta environmental efficiency and declining environmental technology level, the actual agricultural growth of Guizhou has benefited to a great extent from the increase of its factor input. Among the groups of central China, Henan has witnessed the most significant improvement of both RGEE and RMEE, respectively, by $0.3023 \%$ and $0.4835 \%$, and the change rate of meta-technology ratio (RMTR) has also increased by $0.2994 \%$, which indicates that the agricultural growth of Henan has benefited to a great extent from the improvement of its environmental efficiency and environmental technological level. Anhui has witnessed the most significant decline of both RGEE and RMEE, respectively, by $0.1495 \%$ and $0.3581 \%$, and the change rate of meta-technology ratio (RMTR) has also showed a trend of decline, dropping $0.2480 \%$, which similarly indicates that, under the circumstance of underperforming environmental technological catch-up and environmental efficiency, factor input accumulation is still the main source of agricultural growth for Anhui.

\section{Test of the EKC Curve of the Agricultural Environment}

\section{Regression Model}

Our paper has measured the agricultural environmental efficiency of China. Next we need to verify whether the agricultural environment China EKC curve exist and explore its characteristics, at the same time analyzing the cause of regional differences in agricultural environmental efficiency, in order to find the driving mechanism of agricultural environmental efficiency.

In order to reflect the production process from agricultural input to agricultural output and resolve the contradiction between the existing resources and environment and the agricultural growth through comprehensive arrangement, in this paper, the explained variable of the EKC model was defined as agricultural environmental efficiency. The explained variable includes the agricultural growth level and its square, so it's called the quadratic equation model of EKC; if the explained variable further includes the cube of the agricultural growth level, it will be called the cubic equation model of EKC. In this paper the quadratic equation model of agricultural EKC was first tried, and was replaced by the cubic equation model for improvement when it became insufficient. In addition to the agricultural economic growth indicator, five control variables were also selected in this paper, i.e., openness of trade, proportion of agriculture, agricultural technological level, income gap, and fiscal support to agriculture. The regression model is as follows:

$$
\begin{aligned}
& \ln T E_{i t}=\mu_{i}+\theta_{t}+\beta_{1} \ln \text { agri }_{i t}+\beta_{2} \ln \text { agri }^{2}{ }_{i t}+\beta_{3} \ln \text { inco }_{i t}+ \\
& +\beta_{4} \ln \text { open }_{i t}+\beta_{5} \ln \text { pate }_{i t}+\beta_{6} \ln \text { stru }_{i t}+\beta_{7} \ln \text { fina }_{i t}+\varepsilon_{i t}
\end{aligned}
$$

...where the subscripts $i$ and $t$ respectively represent the $i^{\text {th }}$ province and $t^{\text {th }}$ years, $\mu_{i}$ represents the cross-section effect of a specific region, $\theta_{t}$ represents a specific clocking effect, and the explained variable represents the agricultural environmental efficiency $\left(T E_{i i}\right)$ of province $i$ within time $t$. When $h=m e t a, T E_{i t}^{h}$ represents the meta environmental efficiency of various provinces (regions); when $h=$ group $-k, T E_{i t}^{h}$ represents the group environmental efficiency of various provinces (regions) of the three groups. In $\operatorname{agri}_{i t}$ is the agricultural growth variable, and can be used to determine the relationship between agricultural growth and environmental efficiency through the regression coefficient: when $\beta_{1}>0$ (or $\beta_{1}<0$ ) and $\beta_{1}=0$, there is a monotonic increase (decrease) relationship; when $\beta_{1}>0$ and $\beta_{1}<0$, there is an inverted $\mathrm{U}$-shaped relationship; when $\beta_{1}<0$ and $\beta_{1}>0$, there is a U-shaped relationship.

The data used were collected from China Statistical Yearbook, China Rural Statistical Yearbook, China Agriculture Yearbook, and China Statistical Yearbook on Science and Technology in the sample period from 1998 to 2013 .

\section{Selection of Variables}

According to the different explained variables, we respectively estimate the panel model, namely meta environmental and group environmental efficiencies of eastern, central, and western China. Each model includes estimation of random and fixed effects. But the Hausman test result in the four models show that the fixed effect is better than random effects. In addition, we also use Hausman to test the endogenous variables and the endogenous test $\mathrm{P}$ value result of the above four panel model rejecting the endogenous assumption. Considering the limit of paper length, we only report the estimation results of the fixed effect model.

Agricultural economic growth is represented by the per capita agricultural output value of each province, and adjusted by the total agricultural output value index of previous years to eliminate the impact of inflation factors. The openness of trade of the agricultural sector is represented by the proportion of the total import and export value of agricultural products of each province (region) in the total agricultural output value, and the total 
Table 3. Panel estimation results of factors influencing agricultural environmental efficiency.

\begin{tabular}{|c|c|c|c|c|}
\hline \multirow{3}{*}{ Explanatory variables } & \multirow{2}{*}{ Whole country (TE $\left.E^{\text {meta }}\right)$} & \multicolumn{3}{|c|}{ Three regional groups } \\
\hline & & East $\left(T E^{\text {group }-k}\right)$ & Central $\left(T E^{\text {group }-k}\right)$ & West $\left(T E^{\text {group }-k}\right)$ \\
\hline & Coefficient & Coefficient & Coefficient & Coefficient \\
\hline$c$ & $1.435^{* * *}$ & $0.876^{* * * *}$ & $1.232^{* * *}$ & $0.908^{* * *}$ \\
\hline $\ln a g r i$ & $-1.212^{* * *}$ & $-1.765^{* * *}$ & $-1.532^{* * * *}$ & $-1.557^{* * *}$ \\
\hline $\ln a g r i^{2}$ & $0.074^{* * *}$ & $0.113^{* * *}$ & $0.080^{* * *}$ & $0.083^{* * *}$ \\
\hline $\ln$ inco & $-0.034^{* * * *}$ & $-0.013^{* * *}$ & $-0.038^{* * * *}$ & $-0.052^{* * *}$ \\
\hline $\ln$ open & 0.134 & $0.054^{* *}$ & $-0.027^{*}$ & $-0.049^{*}$ \\
\hline $\ln$ pate & 0.189 & $0.024^{* * *}$ & 0.077 & 0.035 \\
\hline ln stru & $0.062^{* * *}$ & $0.065^{* * *}$ & $0.145^{* * *}$ & $0.112^{* *}$ \\
\hline $\ln f i n a$ & $-0.045^{* * *}$ & $-0.031^{* * *}$ & $-0.065^{* * *}$ & $-0.054^{* *}$ \\
\hline n $F$ value & 103.23 & 89.03 & 79.76 & 92.21 \\
\hline Adjust $R^{2}$ & 0.6024 & 0.7865 & 0.6987 & 0.7243 \\
\hline Endogenous test & 0.1190 & 0.8943 & 0.9213 & 0.8854 \\
\hline Hausman $\chi^{2}$ & 165.65 & 89.45 & 94.54 & 108.03 \\
\hline Turning points & 9,454 & 4,734 & 6,657 & 6,302 \\
\hline
\end{tabular}

Note: $* * *, * * *$ represent significance levels of $10 \%, 5 \%$, and $1 \%$, respectively.

agricultural output value is converted by the exchange rate of each year. The proportion of agriculture is represented by the total agricultural output value of each province (region) in the total output value, and adjusted respectively by local agricultural output value index and local total output value index. The agricultural technological level is represented by the $R \& D$ appropriation expenditure of the agricultural scientific research institutions of each province. The income gap is represented by the per capita income ratio of urban and rural residents of various provinces, and adjusted to take into account urban and rural consumer price indexes (CPIs), respectively. Fiscal support of agriculture is represented by the proportion of the fiscal expenditure of a local government in the local total agricultural output value.

\section{Analysis of Test Results}

In the Meta environmental efficiency model (as sshown in Table 3), the linear term and quadratic term coefficient signs of agricultural growth variable were, respectively, the negative sign and the positive sign, and passed the $1 \%$ significance test, which suggested that there was a U-shaped curve between agricultural growth and environmental growth, which was similar to that of EKC, with the turning point occurring around 9,454 Yuan RMB. This also meant that when the per capita agricultural output value was below 9,414 Yuan RMB, agricultural environmental efficiency began to decline with agricultural growth; however, after the per capita agricultural output value exceeded the lowest turning point the agricultural environmental efficiency would continuously rise with agricultural growth. As far as China's actual regional distribution of the per capita agricultural output value is concerned, in 2013 the per capita agricultural output value was 4,428 Yuan RMB, and the per capita agricultural output values of all provinces were lower than the turning point. As a whole we are still in the decline stage of the U-shaped curve, i.e., agricultural environmental efficiency will deteriorate with agricultural growth.

Similar to the results of Meta environmental efficiency, there was also a U-shaped curve characteristic between agricultural growth and environmental efficiency of the three groups, which also validated that the estimated results of meta environmental efficiency were robust. Although the curves of the three groups were consistent in morphology, their lowest turning points were different, i.e., the turning points of eastern, central, and western China were, respectively, 4,734, 6,657, and 6,302 Yuan RMB. Specifically, the turning points of both central and western China were significantly higher than that of eastern China, which suggested that, due to the gap in environmental production technology, the underdeveloped central and western China would face higher agricultural output value thresholds in the course of realizing the transition of its environmental efficiency from decline to rise. As can be seen from the individual circumstances of the three groups, in 2013 the per capita agricultural output values of eastern, central, and western China were, respectively, 4,082, 4,996, and 4,329 Yuan RMB, which indicated that, in the average sense, eastern China was already approaching its turning point by 2013 and thus would be the first to step onto the rising stage of the U-shaped agricultural EKC curve. 
Then how to interpret the U-shaped curve characteristics between agricultural growth and environmental efficiency? Next we will discuss the effects of control variables respectively related to meta environmental efficiency and group environmental efficiency.

Income gap: in the meta environmental efficiency model, the urban-rural income gap coefficient was -0.034 and passed the $1 \%$ significance level, which suggested that the widened urban-rural income gap led to the degradation of the agricultural environment. The continuous widening urban-rural income gap compelled the farmers to increase the input of production factors like pesticides and fertilizers in unit area to increase agricultural output, which certainly would aggravate the agricultural non-point source pollution discharge. In the group environmental efficiency model, the urban-rural income gap of eastern China was obviously smaller than that of central and western China, and the environmental production technology level of eastern China was higher, so the negative impact of the urban-rural income gap causing environmental degradation in eastern China would be lower.

Openness of trade: international trade would affect the local ecological environment to a certain extent, but the effect was uncertain. Williams and Shumway (2000) [24] found that trade liberalization stimulated the applied amounts of both fertilizers and pesticides in the USA and the amount of fertilizers in Mexico. However, the application amount of pesticides in Mexico decreased as a result. The openness coefficient in the Meta environmental efficiency model was insignificant, but its effect on the environmental efficiency of different groups varies widely. The coefficient of the eastern China group was significantly positive, which might be due to the strict regulation of agricultural product environment in developed countries (like minimum residue standards on pesticides and fertilizers) urging eastern China to accelerate the promotion and generalization of agricultural technology and improve production processes and technology of agricultural chemical inputs so as to satisfy the quality demands on exported agricultural products. Furthermore, Eastern China enjoyed obvious regional advantages in absorbing advanced environmentally friendly technology from foreign countries, which further improved agricultural productivity and technology and reduced the environmental pollution caused by agricultural production. However, the coefficients of central and western China were negative, and they passed the significance level only under $10 \%$ conditions, but to a certain extent this suggested that the increase of the trade volume of agricultural products would lead to environmental deterioration. This was because, due to the lag of central and western China in environmental production technology, only factor input could be relied on to expand the trade scale, increase trade volume, and improve agricultural output, which inevitably would increase both the consumption of resources and the discharge of pollutants.

Proportion of agriculture: in the meta environmental efficiency model the coefficient of the proportion of agriculture was significantly positive, which suggested that, although the share of agriculture gradually declined, agricultural environmental efficiency decreased progressively. In the group environmental efficiency model, such characteristics of the central and western groups were even more obvious. As restrained by the shortage of land resources and the massive loss of young and middle-aged labor force in the rural area, agricultural production could only rely on increasing the application amounts of pesticides and fertilizers in unit area to increase agricultural output so as to alleviate the impact of the shortage of both resources and labor force.

Agricultural technological level: in the meta environmental efficiency model the agricultural technological improvement factor failed to pass the significance test. This suggested that both environmentally friendly and non-environmentally friendly technologies emerged in the developmental course of agricultural technology, as a result of which the effect of agricultural technological improvement in alleviating the discharge of agricultural non-point source pollutants was not so obvious. For eastern China, the coefficient was 0.024 and passed the $1 \%$ significance level, which suggested that the environmentally friendly effect of agricultural technological improvement was embodied to a certain extent in eastern China: first, the pollution reduction goal was achieved by technological improvement through replacing or reducing resource consumption; second, technological improvement contributed to the improvement of resource utilization methods; third, professional pollution control technology provided effective approaches for solving environmental problems.

Fiscal support to agriculture: in both the meta environmental efficiency model and the group environmental efficiency model, the coefficients of fiscal support to agriculture were significantly negative, which suggested that, with the increase of the proportion of the expenditure for supporting agriculture (including the expenditure for price subsidies) in total national fiscal expenditure, agricultural environmental efficiency decreased as a result. Agricultural development cannot do without fiscal support, but inappropriate support policies may also negatively affect agricultural production to a certain extent. Therefore, it is imperative to reform agricultural support policies by such means as linking up subsidy policies with the ecological developmental direction of agriculture and introducing ecological agriculture-related evaluation indicators.

\section{Conclusion and Suggestions}

In this paper, the gap in environmental technology and spatial spillover were incorporated into the analysis framework designed to test the EKC curve of the traditional agricultural environment in order to investigate the EKC curve characteristics and spatial effects of agricultural environmental efficiency under different environmental technological levels. First, differences did exist among different groups in the levels of agricultural 
environmental production technology, and due to the significant differences in agricultural environmental production technology among different groups, agricultural environmental efficiency presented a pattern of progressive decline, i.e., eastern China $>$ western China $>$ central China. This also suggests that, for those major agricultural provinces in central China where intensive cultivation has led to higher input of both pesticides and fertilizers, it is of vital importance to improve the level of agricultural environmental production technology and establish a highly efficient and environmentally friendly agricultural technology and promotion system.

Second, U-shaped curve characteristics similar to that of EKC between agricultural growth and environmental growth was present in all cases. In other words, with agricultural growth, agricultural environmental efficiency began to decline; however, after agricultural growth exceeded the turning point, agricultural environmental efficiency would continuously rise with agricultural growth. However, as a result of the environmental production technology gap, the curves of different regions presented different turning points and stages. What needs special attention here is that the U-shaped agricultural EKC curve cannot be employed as an excuse for the traditional thinking of "Pollution first, treatment later" in the course of agricultural pollution. With agricultural growth both the application of fertilizers and pesticides and the discharge of pollution will decrease, but such a process will not automatically happen. If no positive solutions are employed, not only will the occurrence of the turning point of the U-shaped curve be delayed, but the significance of the rising trend of the U-shaped curve will be reduced as well. So, in the course of establishing agricultural industry policies and agricultural environmental-protection policies, the government should, in respect to the actual circumstances of different regions, flexibly carry out various measures to accelerate the transformation of the agricultural production mode by means of increasing the efficiency of fiscal expenditure for supporting agriculture, enhancing the R\&D of agricultural technology, and reducing the urban-rural income gap.

\section{References}

1. GROSSMAN G.M., KRUGER A.B. Economic Growth and the Environment. Quarterly Journal of Economics. 10 (7), 1995.

2. KAHN M.E. A household level environmental Kuznets Curve. Economics Letters., 59 (2),1998.

3. SOYTASO U., SARI R. Energy consumption, economic growth, and carbon emissions: challenges faced by an EU candidate member. Ecological Economics., 68, 2009.

4. PARK S.L., YOUNG M. Regional model of EKC for air pollution: Evidence from the Republic of Korea. Energy Policy, 33, 2011.

5. SEPHTON P., MANN J. Further evidence of an Environmental Kuznets Curve in Spain. Energy Economics. 36, 2013.

6. GIOVANI S., ELEHTHERIO S. Environmental Kuznets curve: Evidence from the British Household Panel Survey.
Economic Modelling. 30, 2013.

7. WANG Y.C. Functional sensitivity of testing the environmental Kuznets curve hypothesis. Resource and Energy Economics. 35 (4), 2013.

8. MUHAMMAD S., NACEUR K., GAZI S.U., IIHAN O. Environmental Kuznets curve in an open economy: A bounds testing and causality analysis for Tunisia. Renewable and Sustainable Energy Reviews. 34, 2014.

9. WANG L.J., ZHOU D.Q., WANG Y.Y. An empirical study of the environmental Kuznets curve for environmental quality in Gansu province. Ecological Indicators., 56, 2015.

10. NICHOLAS A., IIHAN O. Testing Environmental Kuznets Curve hypothesis in Asian countries. Ecological Indicators. 52, 2015.

11. MEHDI B.J., SLIM B.Y. The environmental Kuznets curve, economic growth, renewable and non-renewable energy, and trade in Tunisia. Renewable and Sustainable Energy Reviews. 47, 2015

12. JUNGHO B., Environmental Kuznets curve for $\mathrm{CO}_{2}$ emissions: The case of Arctic countries. Energy Economics. $50,2015$.

13. ZHANG H., YU Y., HU H. Economy growth and agricultural non-point source pollution: an empirical analysisi:based on provincial panel data. Energy Procedia. 5, 2011.

14. CAO D.Y., LI G.C. An Empirical Research ON the Agricultural Environmental Kuznets Curve in China: Estimation Based on Simultaneous Equation Model. Soft Science. 7, 2011.

15. WANG S.Y., LU W.C.The relationship between income and NSP in zhejiang province: Is there an environmental Kuznets curve? Energy Procedia. 5, 2011.

16. ABDOULKARIM E., FATEMEH N. Deforestation and the Environmental Kuznets Curve in Iran.Small-scale Forestry, 13 (3), 2014.

17. SILVIA C., ROBERTO E. Is There a Long-Term Relationship Between Agricultural GHG Emissions and Productivity Growth? A Dynamic Panel Data Approach. Environmental and Resource Economics. 58 (2), 2014.

18. ZAIM O., TASKIN F. A Kuznets Curve in Environmental Efficiency: An Application on OECD Countries. Environmental \& Resource Economics. 17 (1), 2000.

19. HAILU A., VEEMAN T.S. Non- parametric Productivity Analysis with Undesirable Outputs: An Application to the Canadian Pulp and Paper industry. American Journal of Agricultural Economics. 83 (4), 2001.

20. FARE R., GROSSKOPF S., PASURKA C.A. Environmental Production Functions and Environmental Directional Distance Functions. Energy. 32 (2), 2007.

21. LAI S.Yi., DU P.F. Evaluation of non-point Source Pollution based on unit analysis. Journal of Tsinghua University. 9, 2004.

22. ABEDULLAH A. Environmental Efficiency Analysis of Basmati Rice Production in Punjab, Pakistan: Implications for Sustainable Agricultural Development. Pakistan Development Review; 49 (1), 2010.

23. LI G.C. The Coordination of Agricultural Development with Environment and Resource.The Journal of Quantitative \& Technical Economics. 10, 2011.

24. HAYAMI Y. Sources of Agricultural Productivity Gap among Selected Countries.American Journal of Agricultural Economics. 51 (3), 1969.

25. BO H. CHERN C.C., YU M.M. Measuring the relative efficiency of IC design firms using the directional distance function and a meta-frontier approach. Decision Support Systems. 53 (4), 2012.

26. TUNC A., KARACUK A., CATI K. A meta-frontier 
approach to measure productivity differences of domestic and foreign affiliated firms. Journal of Business Economics and Management. 14 (4), 2013.

27. WANG Q.W., ZHAO Z.Y. ZHOU P., ZHOU D.Q. Energy efficiency and production technology heterogeneity in China: A meta-frontier DEA approach. Economic Modelling. 35, 2013.

28. SUSILA M., BEHROUZ A. Eco-efficiency change in power plants: using a slacks-based measure for the meta-frontier Malmquist-Luenberger productivity index. Journal of Cleaner Production. 105, 2015.

29. YU Y.N., CHOI Y., ZHANG N. Strategic corporate sustainability performance of Chinese state-owned listed firms: A meta-frontier generalized directional distance function approach. The Social Science Journal. 52 (3), 2015.

30. ZOU W.J., CAI P.H., SHEN N., LU C.C. The technology gap of Chinese regions' energy efficiency and spatial convergence - Based on the hybrid meta-frontier data envelopment analysis. Journal of Renewable and Sustainable Energy. 7 (2), 2015.

31. WANG Q.W., ZHOU D.Q., ZHOU P. Regional differences of total factor carbon dioxide emissions performance in China: a study of undesirable output Meta-frontier Function. Finance and Trade Economics. 9, 2010.

32. LIU Y., WU P. Energy Consumption, Carbon Economic Growth in Dioxide Emission and Regional the APEC Eeonomies. Economic Review. 6, 2011.
33. FARE R., GROSSKOPH S., PASURKA C.A. Environmental Production Functions and Environmental Directional Distance Functions. Energy. 32 (2), 2007.

34. TONE K. A Slacks-Based Measure of Efficiency in Data Envelopment Analysis. European Journal of Operational Research. 13 (2), 2001.

35. TONE B. An Equity First, Risk Based Framework for Managing Global Climate Change, Global Environmental Change. 13 (1), 2003.

36. FUKUYAMA W.W. A Directional Slack-based Measure of Technical Inefficiency. Socio-Economic Planning Sciences, doi:10.1016j.scps.2008.12.001.

37. BATTESE G.E., RAO D.S.P. Technology Gap, Efficiency and a Stochastic Meta- frontier Function. International Journal of Business and Economics. 1 (2), 2002.

38. SEIFORD G.E., ZHU J. Modeling Undesirable Factors in Efficiency Evaluation. European Journal of Operating Research. 142 (1), 2002.

39. O'DONNELL C.J., RAO D.S.P., BATTESE G. E. Meta frontier Frameworks for the Study of Firm-Level Efficiency and Technology Ratios. Empirical Economics. 34 (3), 2008.

40. WILLIAMS S.P., SHUMWAY C.R. Trade Liberalization and Agricultural Chemical Use: United States and Mexico. American Journal of Agricultural Economics. 82 (1), 2000. 